\title{
Determinants of Employment Status and Its Relationship to Poverty in Bophelong Township
}

\author{
Steven Henry Dunga \\ School of Economic Sciences, North-West University, Vanderbijlpark, South Africa \\ Email: steve.dunga@nwu.ac.za \\ Mmapula Brendah Sekatane \\ Parliamentary Budget office, National Parliament, Cape Town \\ msekatane@parliament.gov.za
}

Doi:10.5901/mjss.2014.v5n21p215

\begin{abstract}
The paper analyzed the factors that determine the employment status of households in Bophelong Township. Factors such as the level of education, age, gender, marital status and labour force were analyzed to determine their influence on the employment status of the households of Bophelong Township. The employment status was then analyzed to see its relationship to the poverty status amongst the households. The paper used aggregate income of households to determine the status of households with regard to poverty. A logistic regression was used to estimate the determinants of employment status. Of the hypothesised determinants, education level, age, marital status, household labour force and total government grants were found to be significant determinants of employment status. The results showed that there is a significant relationship between employment status and poverty status, with those employed having a better chance of escaping poverty.
\end{abstract}

Keywords: Employment, poverty, logistic regression, Bophelong

\section{Introduction}

Studies on poverty and how best to reduce or eradicate it completely are ubiquitous in the literature. The only differences that exist focus on the contextualisation of the issues and the tailoring of solutions to suit specific situations. There are areas in the solutions to poverty, however, that transcends differences in circumstances, one of which is employment. Sustainable employment is one of the best routes out of poverty. Assistance in designing and implementing strategies and programmes for job creation can contribute to the objective of poverty alleviation or reduction in situations of low income and high unemployment and underemployment (Islam, 2004). Employment is crucial in the sense that it provides a source of livelihood for the majority of people in a capitalist society where capital that enables ownership of production is available to but a few. The owners of the factors of production therefore employ labour as a factor of production and in turn provide those who would otherwise be poor, a chance for a better life (Jacoby, 2007). Employment is however a function of a host of other factors, among them the availability of jobs, and types of jobs, and the size of the sectors available in a particular country or society. On the employee part, there are also factors that determine the probability of getting a job, and the quality of the job(Assaad, et al., 2000). The recognition of the importance of employment in dealing with poverty by the International Labour Organisation (ILO) signifies the importance of employment. Islam (2004) explains that the experience of countries that succeeded in reducing poverty significantly indicates the importance of high rates of economic growth in achieving this. High growth, however, is not a sufficient condition for poverty reduction; the pattern and sources of growth as well as the manner in which its benefits are distributed are equally important from the point of view of achieving the goal of poverty reduction. And employment plays a key role in that context (Islam, 2004).

The rest of the paper is organised as follows; section 2 reviews literature on the determinants of employment status and the relationship between employment and poverty. Section 3 presents the methodology of the data collection and the measurement of poverty. The regression equation is also specified in this section. Section 4 presents the results and discussion and section 5 concludes the paper. 


\section{Literature Review}

Employment is considered one of the main pillars in dealing with poverty (ILO, 2008). Bhorat (2007) investigated on a number of labour economic and social choice theories and identified factors or common variables that determine the chance of somebody to be employed or not. The economic theory states that more education results in a greater likelihood of employment. In many middle and low income countries there is shortage of highly educated individual and this result in high unemployment. Although there is a scarcity of highly-educated people in many African countries (including South Africa), Egypt has surplus of highly-educated people who find it difficult to get jobs. Despite that, there has been a shift away from unskilled/semi-skilled labour towards more skilled labour in low and middle income countries. Employment is affected by choices in how to utilise hours in the day. This is related to household responsibilities such as fetching water, wood, childcare, care of the elderly and leisure activities. Gender and culture have an impact on employment. Women are often more likely to be home-makers dependent on the male of the household. This depends significantly on who is the head of the household or family. The head of the household is often the one who is working and more likely to be the breadwinner. The issue of race also plays a role in many developed and developing countries. In standard neo-classical labour theory, it is argued that high unemployment rate is caused by high wage. This means that if there is involuntary unemployment, the real wage will fall and unemployed people will find a job at a lower wage. The decrease in real wage implies lower costs to employers and it encourages them to employ more workers (Bhorat, 2007).

According to Bhorat (2007) the composition of the household determines unemployment. A household that has many teenagers and babies can have impact on the likelihood of employment by acting as an incentive to find employment. There is a correlation between marital status and employment in both developed and developing countries. It is argued that once a person is married, there is economic and psychological incentive to find employment. Generally, it is viewed that married men are less risky employees because they have settled down. However, this is highly debatable because someone may be employed in the first place and this attracts potential partners to him/her. There is a need to know what happened in the first place. Another factor explaining unemployment is wealth of the family or household. People from poor families have little or no money to actively look for jobs and this causes geographical immobility to areas where jobs are located.

The important role that employment plays in uplifting the lives of the poor is evident in literature (Islam, 2004; ILO, 2008; Hull, 2009). The fact that economic growth without the creation of jobs is a recipe for more unequal distribution and hence more relative poverty has been proven by studies conducted in a number of countries both in Africa and across the globe. A study by Bourguignon (2004) showed that income distribution determines the extent to which economic growth affect poverty reduction. Dollar and Kraay $(2000,2001)$ also pointed out the heterogeneity in the responses of poverty to economic growth which is a result of different inequalities existent in different countries. Other studies that found related results are Gugerty and Roemer, (1997) and Hull (2009). According to Hull (2009), jobs are an important aspect in the effort of poverty reduction. She highlighted the extent of the need to clearly understand how employment and the quality of employment should be factored in, in any poverty reduction discourse to ensure maximum results of any poverty reduction effort.

\section{Methodology}

This section of the paper discusses the survey design and the data collection process. It also explains how poverty was measured to arrive at the poverty status of the households.

\subsection{Survey Design}

This study is based on a household survey using questionnaires. A random sample of households was interviewed in the township of Bophelong. Maps were obtained for area and sample stratification was designed on account of the geographical distribution and concentration of people in the area. A questionnaire was designed for obtaining the desired information. The area was divided into different extensions and the questionnaires were apportioned evenly among the inhabited sites. Sites at which field workers were supposed to complete questionnaires were identified individually from the map before the field workers went out. However, where people could not be obtained for an interview, or where it was impossible to trace the house, a next pre-selected household was interviewed. Information was obtained from the breadwinner or the spouse. Information obtained from the respondents was kept in strict confidence and the participants were not required to write their names on the questionnaire. A total of 300 households were interviewed by two 
fieldworkers in July 2013, only 295 were used in the analysis.

\subsection{Measurement of Poverty}

In order to achieve the objective of finding the determinants of employment status and its relationship to poverty, a measure of poverty was needed. Following the guidelines of the World Bank (2001), a poor household is defined as a household whose combined income of all its members is less than the cost of minimum calorie intake and that of other necessities of the household. Using the information on household size and household total income, the household poverty status was calculated. Following the poverty measure for South Africa for the year 2009 of R416 (STATS SA, 2008/9), and adjusted it for inflation for the year 2013, a per capita poverty line of R520 was determined. The share of the poor and non-poor in the sample was determined at $50.8 \%$ and $49.2 \%$ respectively, half to each category. About $61 \%$ of the heads of households' were found to be unemployed and only $39 \%$ were employed.

In order to find out which variables form the determinants of employment status in Bophelong Township, a logistic regression was used. A logistic regression was chosen due to the nature of the dependent variable, which is categorical. With a categorical variable as a dependent variable, the classical ordinary least squares could not be used. This is explained in the next sub-section.

\subsection{Regression Model}

As a liner regression the goal is to estimate regression coefficients in the chosen model. The dependent variable which is employment status is coded as 1 for employed and 0 for unemployed. The form of the multiple logistic regression is therefore as follows;

$$
L=\ln (o)=\ln \left(\frac{p}{1-p}\right)=\emptyset_{1}+\emptyset_{2} X_{2}+\emptyset_{3} X_{2} \ldots+\emptyset_{n} X_{n}+\varepsilon
$$

Where $E$ is employment and it is a binary variable, $L$ is the In (odds of event), $p$ is the proportion of a heads of households in employment, 0 is the odds of employment and $X_{2}, X_{3} \ldots . X_{n}$ are the independent variables. The intercept is represented by $\emptyset_{1}$ and $\emptyset_{2}+\emptyset_{3} \ldots+\emptyset_{n}$ are slope coefficients. $\varepsilon$ is the random error term. The actual regression estimated is therefor as follows;

$$
\ln \left(\frac{p}{1-p}\right)=\emptyset_{1}+\emptyset_{2} \text { EDu }_{\mathrm{i}}+\emptyset_{3} \text { Age }_{\mathrm{i}}+\emptyset_{4} \text { Gender }_{\mathrm{i}}+\emptyset_{5} \text { MaritalSt }_{\mathrm{i}}+\emptyset_{6} \text { LabourForce }_{\mathrm{i}}+\emptyset_{7} \text { totalGrants }_{\mathrm{i}}+\varepsilon_{\mathrm{i}} \ldots 1
$$

Where, $\mathrm{E}$ is the employment status of the head of household, taking 1 as being employed and 0 as unemployed. The objective of a logistic regression is finding the probability that $E$ will be equal to $1 . \emptyset_{1}$ is the intercept coefficient, $\emptyset_{2 \text { to } 7}$ are coefficients for the hypothesised determinants of employment status namely, Education level, Age of head of household, gender of head of household, Marital Status of head of household, Labour force in the household and total grants received in the household in that order.

\section{Results and Discussion}

\subsection{Determinants of employment status of the head of household}

On the determinants of employment status, the regression results have all the hypothesised variables significant with the exception of the gender of the head of household. Education of the head of household is significant at $10 \%$ significance level. The coefficient of .062 for Education is positive showing that a higher level of education increases the probability of being employed. This is not a unique result as employment is to a greater extent correlated with education levels. Duncan (2013) argued in her article on Education and Employment in South Africa, that well educated workers get better jobs, earn more and are more productive. The productivity part is a debatable proposition, but the other two are easily agreeable. There are a number of other studies that also found a similar result. In The OECD for example, the situation has been getting worse in terms of the chances of getting a job for the people with low qualification or no qualification (Mcintosh, 2008)

The result on age of head of household is significant at $1 \%$ significance level but with a negative coefficient of .068. This means that the older the head of household gets, the lower the probability of being employed. Age reduces the probability of getting a job. This is in agreement with theory where income profiles show a quadratic shape, increasing with age to a certain point and then decline (Becker, 1975; Johnes, 1993)(Becker, 1975; Johnes, 1993). There are other studies that have actually revealed that there is age discrimination in the hiring process, where older people are left out based entirely on their age(Wilson, et al., 2007) 
Marital status was a categorical variable with 1 as an indication of never married. The results show a significant positive relationship at $1 \%$ significance level between marital status and employment status. The positive relationship indicates that those that were never married have a higher probability of being employed. The reason could be that having a job is their only option of being independent as they have no spouse to depend on.

Table 1: Results of the Logistic regression

\begin{tabular}{|l|c|c|c|c|c|c|}
\hline Dependent variable: Employment Status & B & S.E. & Wald & d.f. & Sig. & Exp. (B) \\
\hline Education of household Head & .062 & .033 & 3.641 & 1 & .056 & 1.064 \\
\hline Age of Household Head & -.068 & .013 & 27.190 & 1 & .000 & .934 \\
\hline Gender of Household Head (1) & .571 & .357 & 2.551 & 1 & .110 & 1.769 \\
\hline Marital Status of household Head (1) & 1.532 & .343 & 20.002 & 1 & .000 & 4.628 \\
\hline Labour Force in the household & .669 & .145 & 21.298 & 1 & .000 & 1.953 \\
\hline Total Grants received & .000 & .000 & 7.986 & 1 & .005 & 1.000 \\
\hline Constant & -.151 & .823 & .033 & 1 & .855 & .860 \\
\hline
\end{tabular}

Source: Calculations based on Survey Data (2013)

Labour force in the household has a positive coefficient and it is significant at $1 \%$ significance level. This means that the more people in the house that can work the higher the chance of the head to be in employment. Another interesting relationship is between total government grants received and employment status. Total government grants received have a positive relationship with the probability of the head of household being employed. It could be that the more money they get, the more they realise how better life can be and hence act as a motivation to get employed. The likely expectation is that those that are employed and also receiving grants are working in low skill sectors which pay very little and hence forcing them to depend on grants as well.

The model fit is tested by the Hosmer Lameshow test which compares the $p$ value in this case .568 to a chosen significance level. A regression is a good fit if the $p$ value is greater than a chosen significance level. So a $5 \%$ significance level, the $p$ value of .568 for the regression is significant since the value is greater than 0.05 .

\subsection{Employment status and poverty}

The second objective of the study was to investigate on the relationship between employment status and poverty status among the households in Bophelong. Since both of these two variables are categorical, a chosen analysis was correlation using cross tabulation in SPSS to determine the percentages of those in employment and poor and the percentage of those not employment and poor or not poor. Table 2 presents the results of the tabulation. The table shows that in the sample, $50.8 \%$ of the households are poor and $49.2 \%$ are not poor using the poverty line discussed in subsection 3.2. It also shows that $61 \%$ are not employed while $39 \%$ of the head of households are employed. Of the unemployed heads of households, $61.1 \%$ are poor and $38.9 \%$ are not poor. The $61.1 \%$ poverty rate within the unemployed category shows that employment has a significant influence on whether one end up above or below the poverty line.

The Pearson Chi-Square of the relationship is significant at $1 \%$ significance level. This is similar to the assertion by Klasen and Woolard (2005) who pointed out that employment helps households to move out of poverty. A further analysis into this category showed that of the $31.9 \%$ that are not employed and yet also not poor, $83.3 \%$ of them depend on grants. That is more than $50 \%$ of their income comes from government grants, hence they are able to be above the poverty line although without a job. 
Table 2: The relationship between Employment status and poverty

\begin{tabular}{|c|c|c|c|c|c|}
\hline \multicolumn{6}{|c|}{ Employment Status Head ${ }^{*}$ poverty status Cross tabulation } \\
\hline & & & Poverty & status & \\
\hline & & & non poor & poor & Tolal \\
\hline \multirow{6}{*}{$\begin{array}{l}\text { Employment Status of Head } \\
\text { of household }\end{array}$} & \multirow{3}{*}{ unemployed } & Count & 70 & 110 & 180 \\
\hline & & \% within Employment Status of Head & $38.9 \%$ & $61.1 \%$ & $100.0 \%$ \\
\hline & & $\%$ within poverty status & $48.3 \%$ & $73.3 \%$ & $61.0 \%$ \\
\hline & \multirow{3}{*}{ employed } & Count & 75 & 40 & 115 \\
\hline & & \% within Employment Status of Head & $65.2 \%$ & $34.8 \%$ & $100.0 \%$ \\
\hline & & $\%$ within poverty status & $51.7 \%$ & $26.7 \%$ & $39.0 \%$ \\
\hline \multirow{3}{*}{\multicolumn{2}{|c|}{ Total }} & Count & 145 & 150 & 295 \\
\hline & & \% within Employment Status of Head & $49.2 \%$ & $50.8 \%$ & $100.0 \%$ \\
\hline & & $\%$ within poverty status & $100.0 \%$ & $100.0 \%$ & $100.0 \%$ \\
\hline
\end{tabular}

Source: Calculation based on Survey data (2013)

Within the category of the employed, $65.2 \%$ are not poor and $34.8 \%$ are poor, almost giving a mirror image of the unemployed category. This association which is significant at $1 \%$ significance level imply that those with a job are more likely to be above the poverty line than those without a job. Other studies that found a similar association between poverty and employment are Islam (2004), ILO (2008) and Hull (2009). Also the fact that $34.8 \%$ of those with a job are found below the poverty line indicates the differences in job quality. As pointed out already, this calls for a further analysis in the sectors which these people are working in. A prior expectation will be that the poor $34.8 \%$ that are employed are mostly in the low skill and low paying jobs. Hence, just being employed is not enough to alleviate poverty but the kind of jobs concerned matter as well (Hull, 2009).

\section{Conclusions}

The study investigated the determinants of employment status in Bophelong Township. Of the hypothesised determinants, education level, age, marital status, household labour force and total government grants were found to be significant determinants of whether one is employed or not. Gender of head of household was not significant. All the significant determinants were positive except age which portrayed a negative relationship to the probability of being employed. The study also investigated on the relationship between employment status and poverty status of the household. A poverty line of R520 per capita per month was used based on the official poverty line of R416 in 2009 and adjusted for inflation. The results showed that there is a significant relationship between employment status and poverty status, with those employed having a better chance of escaping poverty. The study also found that there were about $34.8 \%$ households where the head of the household is employed and yet poor. This then pointed to the need of further investigating into the types of jobs people who are reported to be working are involved in. A policy implication would be that it is not the quantity of jobs that can be a good tool to deal with poverty, but the quality of the job too.

\section{References}

Assaad, R., El-hamidi, F., \& Ahmed, A.U. (2000). The determinants of employment status in egypt, (88).

Becker, G. S. (1975). Human Capital: A Theoretical and Empirical Analysis, with Special Reference to Education. New York: National Bereau of Economic Research.

Bhorat, H. (2007). "Unemployment in South Africa: Descriptors and Determinants. Paper Presented to the Commission on Growth and Development", World Bank, Washington DC.

Dollar, D. \& Kraay, A. (2000; 2001), Growth is Good for poor, Development Research group, Washington D.C: World Bank.

Gugerty, M. K, \& Roemer, M. (1997). Does economic growth reduce poverty?,

Technical paper.

Hull, K. (2009). Understanding the Relationship between Economic Growth, Employment and Poverty Reduction. In: OECD-Ed., Promoting pro-poor growth: Employment, OECD, pp. 69-94.

ILO (International Labour Organisation). (2008). "Promotion of rural employment for poverty reduction" International Labour Conference 97th Session, Geneva: International Labour Office.

Islam, R. (2004). The Nexus of Economic Growth, Employment and poverty reduction: an empirical analysis. Geneva: Recovery and Reconstruction Department International Labour Office. 
Jacoby, S. M. (2007). "Management and the Varieties of Capitalism, from The Embedded Corporation: Corporate Governance and Employment Relations in Japan and the United States. Princeton: University Press.

Johnes, G. (1993), The Economics of education, London: The macmillan press LTD .

Klasen, S \& Woolard, I (2005), Determinants of income mobility and household poverty dynamics in South Africa, Journal of Development Studies, Vol 41, No. 5, pp. 865-97.

Mcintosh, S. (2008). Education and employment in OECD countries. Paris.

Mortensen, D.T. (1970), Job Search, the Duration of Unemployment and the Phillips Curve, American Economic Review, Vol 30, pp. 847-862.

STATS SA. (2008/9), Poverty Profile of South Africa: Application of the poverty lines on LCS 2008/2009, Pretoria: Statistics South Africa. Wilson, M., Parker, P., \& Kan, J. (2007). Age biases in employment : hiring Age biases in employment :, 9(1).

World Bank. (2001), Poverty Manual, Washington D.C: The World Bank Group. 